\title{
Editor's introduction to Volume 3
}

To the extent that, all too often, accounts of popular music tend towards the positions occupied by, on the one hand, those sociologies which all but leave out the musical work itself and, on the other, formalist and idealist methods which present it as an isolable 'given', the aim of this volume is to advance at least a little way towards the necessary superseding of that rift. 'Production' is therefore taken here not in a narrowly 'economistic' sense nor as a fashionable translation for the processes of 'purely musical' creation but as referring to all the processes involved in the bringing-into-being of a musical work. If, as Marx argued, 'man himself is the basis of . . . all production which he accomplishes', then

all circumstances ... which affect man, the subject of production, have a greater or lesser influence upon all his functions and activities, including his functions and activities as creator . . . In this sense, it can truly be asserted that all human relations and functions, however and whenever they manifest themselves, influence ... production and have a more or less determining effect upon it. (Marx 1905, pp. 388-9)

\section{The sociologist Janet Wolff has argued cogently that}

we have to operate with a model which posits the mutual interdependence of structure and agency, rather than the primacy of one or other . . . insofar as sociology in general must accommodate the actor-subject, properly theorised, the sociology of art is also a theory of the artistic practice of particular subjects. In the same way, the cultural product loses its character as transcendent . . . somehow mysteriously and inherently present. It is seen instead as the complex product of economic, social and ideological factors, mediated through the formal structures of the text . . . (Wolff 1981, pp. 138-9)

She quotes the literary critic Pierre Macherey:

The various 'theories' of creation all ignore the process of making; they omit any account of production . . . All speculation over man the creator is intended to eliminate a real knowledge: the 'creative process' is [seen as], precisely, not a process, a labour; it is a religious formula . . . You will understand why, in this book, the word 'creation' is suppressed, and systematically replaced by 'production'. (A theory of Literary Production (1978), quoted in Wolff 1981, p. 138) 
Of course, a volume such as this could hardly pretend to accomplish a comprehensive account of 'all human relations and functions ... which influence . . . [popular music] production' (in any case the state of popular music study is not at a stage which would make such comprehensiveness even a remote possibility); but it does draw in some outlines at some points on the map. A second problem is that the process of production itself is not fully isolable: 'Consumption produces production ... because a product ...., unlike a mere natural object, proves itself to be, becomes, a product only through consumption. Only by decomposing the product does consumption give the product the finishing touch' (Marx 1973, p. 91). It is out of this consideration that our title, 'Producers and Markets', arises. Throughout the volume there is an awareness, implicit or explicit, that musical products are produced for markets and are consumed by audiences that the significance of musical products is at least partly created at the moment of their use; this point leads on to the subject of the next issue, 'Performers and Audiences', and in this sense, Volumes 3 and 4 should be seen as (necessarily separated) siamese twins.

The contributions to this volume are divided into three groups. The division is to some extent rough and ready, since the differing factors in the processes of production are ultimately connected; nevertheless, it is the case that some studies concentrate, for instance, on the institutional organisations and practices responsible for the production and dissemination of popular music, others on the processes and modes of production themselves - these are the areas covered by the second and third groups of articles, respectively. The historical span covered there is recent, primarily the last twenty years. Two studies treating aspects of the pre-contemporary period make up part one.

The record industry already figures large in the part one articles by Mark Hustwitt and Roger Hewitt, and it is the dominant factor throughout part two. Pekka Gronow sets the scene with a survey of the growth of the industry, world wide, from its beginnings. Subsequent pieces examine various manifestations of its activities in particular regions, all, interestingly, what one might term 'peripheral' regions: Wales, Japan, Hungary (the centre of the industry's operations, the multi-national companies based in the USA and the UK, seems, curiously, to be relatively free from the attention of research). However, the final article in this section, Jon Stratton's, examines what he takes to be the core ideology of the industry as a whole.

This leads neatly into the concerns centrally addressed in part three; indeed these can be read against and in the light of the institutional framework sketched in part two. Antoine Hennion describes the methods used by the 'mainstream' pop record industry in France in 
order to achieve commercial success. The nature of the recording medium is intimately bound up in this, of course, and the next two contributions both, in very different ways, look at this: Paul Clarke through an examination of its effects on the performance of rock music, particularly lyrics, together with the implications for the way we should analyse rock products, and $\mathrm{H}$. Stith Bennett through discussion of the relationships between recording and the nature of contemporary popular music, seen in a broad historical context. Finally, Richard Middleton's article examines a particular aspect of musical processes - repetition - in an attempt to discover the combination of determinants responsible for its production and effects.

\section{References}

Marx, K. 1905. Theories of Surplus Value, published as Theorien über den Mehrwert, ed. K. Kautsky, 3 vols. (Stuttgart) 1973. Grundrisse (Harmondsworth)

Wolff, J. 1981. The Social Production of Art (London) 